\title{
Source characteristics of ocean infragravity waves in the Philippine Sea: analysis of 3-year continuous network records of seafloor motion and pressure
}

\author{
Yoko Tono ${ }^{1 *}$, Kiwamu Nishida ${ }^{2}$, Yoshio Fukao ${ }^{3},{\text { Akiko } \text { To }^{3} \text { and Narumi Takahashi }}^{3}$
}

\begin{abstract}
Continuous 3-year records of broadband ocean-bottom seismometers and pressure gauges of the seafloor network (Dense Oceanfloor Network System for Earthquakes and Tsunamis (DONET)) in the Nankai Trough region made it possible to monitor incoming ocean infragravity $(\mathrm{IG})$ waves. Application of a slant-stacking technique revealed that the most energetic IG waves are incoming across the Nankai Trough from the Philippine Sea with limited energy of reflected waves back from the nearest coast. The sources of the most energetic waves are narrowly and stably localized into two closely adjacent azimuthal windows with mutually different wave spectral characteristics. Both sources show a seasonal variation, weak in summer and strong in winter. Although less energetic, IG waves propagating parallel to the trough and coast are observed. Such waves are greatly amplified when IG waves from a distant typhoon are incoming to the trough, suggesting the secondary origin of IG waves that can emit even more energetic waves than the originally incoming waves.
\end{abstract}

Keywords: Infragravity wave; Seafloor network; Pressure gauge; BBOBS; DONET; Philippine Sea

\section{Findings}

Introduction

Ocean infragravity (IG) waves are sea surface gravity waves with periods of several minutes and wavelengths of tens of kilometers. The phase velocity of IG waves observed in deep ocean environments is accurately explained by the gravity wave theory (e.g., Webb et al. 1991). These waves are considered to be excited by non-linear interactions between oceanic swells (Longuet-Higgins and Stewart 1962; Herbers et al. 1995) and may be enhanced by tidal modulation in coastal oceans (Guza and Thornton 1982; Okihiro and Guza 1995; Tomson et al. 2006) and deep sea (Sugioka et al. 2010). IG waves also are considered to excite the Earth's hum (Rhie and Romanowicz 2004, 2006; Tanimoto 2005; Nishida et al. 2008; Fukao et al. 2010; Nishida 2013).

\footnotetext{
* Correspondence: tono@jamstec.go.jp

'Department of Deep Earth Structure and Dynamics Research, Japan Agency for Marine-Earth Science and Technology, 3173-25, Showa-machi,

Kanazawa-ku, Yokohama, Kanagawa 236-0001, Japan

Full list of author information is available at the end of the article
}

Dolenc et al. (2005) compared the power spectra of ocean-bottom seismic records at a station located offshore of the Monterey Bay in California with the wave spectral densities measured by the nearby National Oceanic and Atmospheric Administration (NOAA) buoy. They observed two types of IG wave modulations with short (30- to 40-s) and long (10-day) periods, the latter being correlated with the ocean tides at the station. Sugioka et al. (2010) also observed the tidal modulation of IG waves on the records of broadband ocean-bottom seismometers (BBOBS) at deep seafloors. They further found a remarkable correlation of the IG spectral peak with the seafloor depth. Godin et al. (2013) showed a pronounced dependence of the energy density of IG wave on the frequency and local water depth using pressure gauge records of 28 locations on the seafloor off New Zealand. Harmon et al. (2012) used five differential pressure gauges located off the coast of Sumatra and applied an array analysis. They detected IG waves that propagate along the coast from southeast or south. Crawford et al. (1991) took advantage of a simultaneous measurement of sea-bottom pressure and seafloor displacement at 
a single station. They measured the sea-bottom pressure changes due to IG waves and the resultant seafloor vertical displacement to take their ratio (compliance) which carries information about the elastic structure of the oceanic crust. When we analyze the sea-bottom pressure and/or seafloor displacement, IG waves, a ubiquitous phenomenon on the sea, can be a strong background noise. Understandings of IG wave-related phenomena are important from the view point of seismology as well as oceanography.

A submarine cable network named the Dense Oceanfloor Network System for Earthquakes and Tsunamis (DONET) was recently deployed offshore of the Kii Peninsula in the Nankai Trough region (Kaneda 2010; Kawaguchi et al. 2010; Nakano et al. 2013). This network is equipped with six instruments at each station, including a three-component BBOBS and an absolute pressure gauge. Thus, DONET provides a good opportunity for array-based compliance analysis to study the crustal structure beneath the network, the generation mechanisms of IG waves, and the IG wave-related seismic phenomena including the Earth's hum. In this study, we investigate the nature of incoming IG waves to DONET on the basis of continuous 3-year observations.

\section{Data and method}

DONET is an ongoing project and currently consists of five nodes, each of which consists of four stations. Figure 1 shows the station distribution of this network and the seafloor topography in the Izu-northern Bonin region. The station interval is 15 to $20 \mathrm{~km}$, on the order of the wavelengths of targeted IG waves of our interest. The four stations at $\mathrm{C}$ node are set at seafloor depths between 3,500 and 4,400 m, while 16 stations at other nodes are positioned at depths between 1,900 and 2,500 $\mathrm{m}$. The average of theoretical phase velocities of IG wave calculated at a period of $120 \mathrm{~s}$ for all stations is $135 \mathrm{~m} / \mathrm{s}$ with a standard deviation of $14 \mathrm{~m} / \mathrm{s}$, while the average of phase velocities at the same period for 16 stations at other nodes is $129 \mathrm{~m} / \mathrm{s}$ with a standard deviation of $4 \mathrm{~m} / \mathrm{s}$. We regarded the 16 stations as an array and analyzed the records of broadband ocean-bottom seismometers (Guralp CMG-3 T, Guralp Systems, Reading, UK) and quartz pressure gauges (Paroscientific, Inc., Redmond, WA, USA) from January

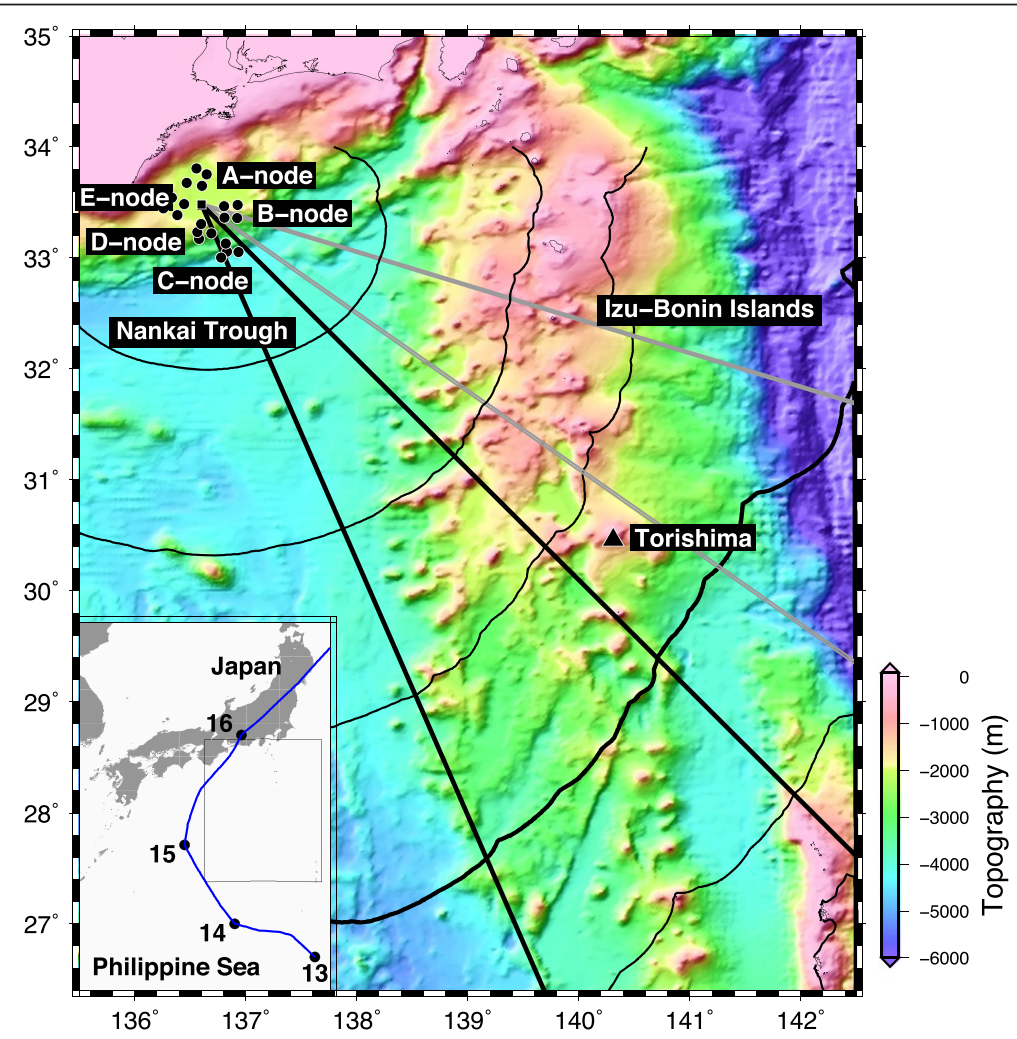

Figure 1 Distribution of DONET stations and submarine topography. The map in the inset shows the location of close-up region, and the blue line shows the track of Typhoon Man-yi from 13 to 17 September, 2013. The color contour is consistent with the marine depth. The black circles show the stations. The A, B, D, and E nodes are located at a depth of approximately 2,000 m, whereas the $C$ node is located approximately $4,000 \mathrm{~m}$ deep. The square indicates the midpoint of the array of all the stations of the A, B, D, and E nodes. The wave front of a very long-period IG wave hypothetically emanating from the midpoint of the array is shown for every 15 min of travel time. The two gray and black lines show the azimuthal windows of $110^{\circ}$ to $130^{\circ}$ (ESE) and $140^{\circ}$ to $160^{\circ}$ (SSE), respectively. 
2011 to December 2013. For each station, both records were band-pass-filtered between 0.005 and $0.025 \mathrm{~Hz}$ and were corrected for the instrumental response. Both displacement and pressure time series were divided into segments of 3,600 s with an overlap of $1,800 \mathrm{~s}$. Segments including earthquake signals, artificial noise, and boisterous noise disturbances due to extreme weather or nearby typhoon activity were discarded. The record sections at various stations were mutually shifted according to a presumed slowness vector and were then stacked. Each slant-stacked record section was auto-correlated and Fourier-transformed to obtain a power spectrum. The same procedure was repeated with numerous slowness vectors to obtain a two-dimensional frequency-slowness spectrum (e.g., Rost and Thomas 2002; Nishida et al. 2005), and all similarly obtained spectra for 1 day were stacked. The pressure records were similarly processed. The power spectral density (PSD) of either seafloor displacement or pressure was averaged over the analyzed frequency range to obtain the average PSD as a slowness vector function. We searched for the slowness vector that maximizes the average PSD. The direction and amplitude of such a slowness vector were regarded as the incident azimuth and apparent slowness of the incoming IG waves, respectively.

\section{Result}

Figure 2a shows an example of the comparison of the seafloor records of vertical displacement (black) and pressure (red). Both were band-pass-filtered between
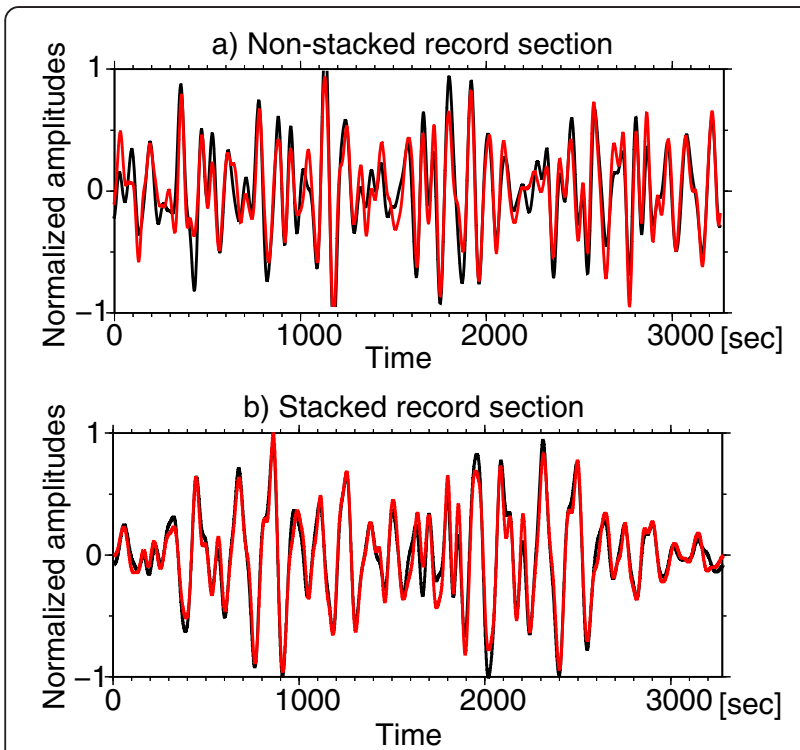

Figure 2 Examples of records sections of vertical displacement (black) and pressure (red). They are band-pass-filtered between 0.005 and $0.025 \mathrm{~Hz}$ on 1 January, 2013. (a) Single-station records and (b) slant-stacked records by an appropriately chosen slowness vector. Each of the records is normalized by its maximum value. The polarity of the pressure record is reversed.
0.005 and $0.025 \mathrm{~Hz}$ and were normalized by the maximum amplitude of each trace, and the polarity of the pressure record was reversed. The agreement between the two traces was remarkable, which was expected if the signal is an IG wave whose phase velocity is much lower than that of a seismic wave (Crawford et al. 1991). Figure $2 \mathrm{~b}$ shows an example of comparison of the stacked records of vertical displacement (black) and pressure (red). Stacking was accomplished by using a slowness vector that makes the stacked IG wave most energetic. The determined slowness value was consistent with that expected from the seafloor depth and the observed frequency range. This consistency, coupled with the remarkable waveform match shown in Figure 2, offered the most direct support for our interpretation of the observed disturbance as the IG waves. The station configuration and the response function of this array at $0.01 \mathrm{~Hz}$ (Rost and Thomas, 2002) are shown in Figure 3. The response function is represented in the slowness vector domain, where its spread around the origin indicates how narrowly in absolute value and how unbiasedly in azimuthal direction the slowness vector can be constrained by the array. The response function of our array is sharp and isotropic enough to warrant further analyses.

Figure 4 shows four examples of the average PSD distribution in the slowness vector domain. Highly similar diagrams were also obtained for seafloor displacement fluctuation, as expected from the waveform match between the displacement and pressure records (Figure 2). Figure 4a,b shows typical patterns in winter, Figure 4c shows the typical pattern in spring, and Figure $4 \mathrm{~d}$ shows a pattern when a typhoon was located in the Philippine Sea approximately $1,000 \mathrm{~km}$ to the south of the network. All the figures show a relatively large power between two dashed circles with slowness values of 7 and $9 \mathrm{~s} / \mathrm{km}$, or phase velocity values of 140 and $110 \mathrm{~m} / \mathrm{s}$, respectively, indicating that the observed waves are IG waves within a

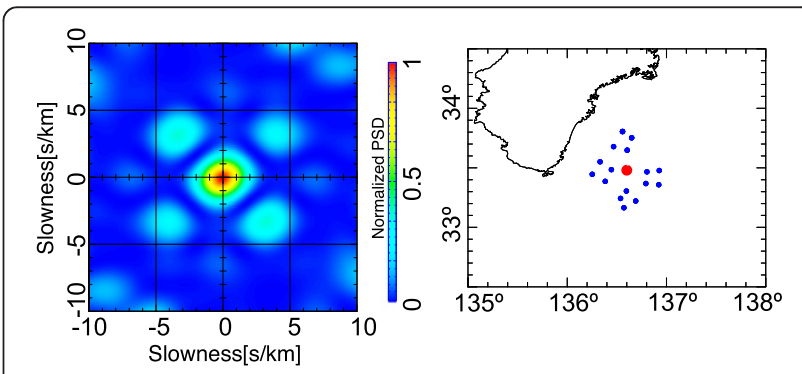

Figure 3 Array configuration (right) and array response function at $0.01 \mathrm{~Hz}$ represented in the relative slowness vector domain (left). In the right, the blue and red circles are the 16 stations used in the analysis and the midpoint of this array, respectively. In the left, the amplitude of the PSD is normalized by the maximum value as shown by the color bar. 

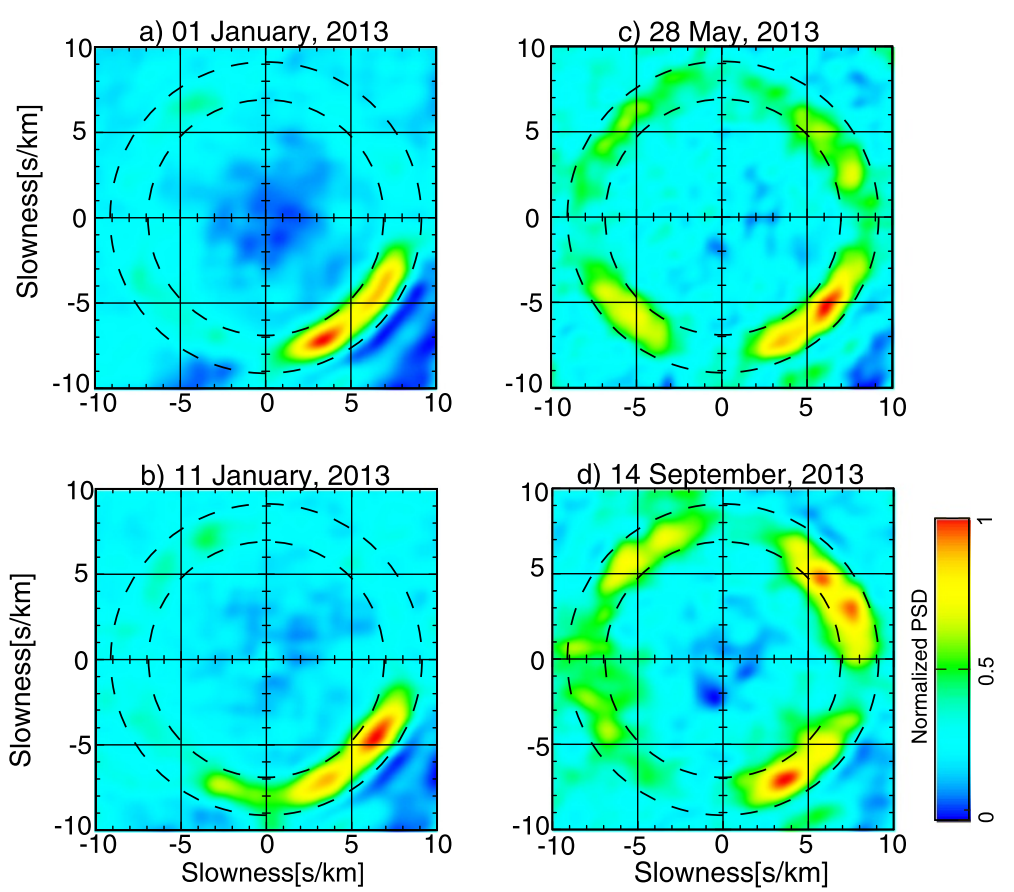

Figure 4 Four examples of the average PSD distribution in the slowness vector domain. The average of PSD is taken over a frequency range between 0.005 and $0.025 \mathrm{~Hz}$. The recorded day is shown at the top of each diagram. The radii of two dashed circles indicate the slowness values of 7 and $9 \mathrm{~s} / \mathrm{km}$. The amplitudes of the PSDs in each diagram are normalized by their maximum value. The slowness (incoming direction, velocity) values estimated from the position of the red peak are (a) $7.9 \mathrm{~s} / \mathrm{km}\left(153^{\circ}, 127 \mathrm{~m} / \mathrm{s}\right) ;$ (b) $7.8 \mathrm{~s} / \mathrm{km}\left(125^{\circ}, 128 \mathrm{~m} / \mathrm{s}\right)$, (c) $8.0 \mathrm{~s} / \mathrm{km}\left(131^{\circ}\right.$, $126 \mathrm{~m} / \mathrm{s})$, and (d) $7.8 \mathrm{~s} / \mathrm{km}\left(153^{\circ}, 128 \mathrm{~m} / \mathrm{s}\right)$.

frequency range of 0.005 to $0.025 \mathrm{~Hz}$ propagating through the ocean at depths around 2,000 m. The IG signal intensity is persistently highest for the incoming waves crossing the Nankai Trough from the southeast (SE). This incoming direction actually consists of two closely adjacent directions: the south-southeast (SSE) and east-southeast (ESE) (see Figure 5 for a histogram of the measured incoming direction). Waves from the SSE direction through the deeper ocean are usually more energetic (Figure 4a) but are at times less energetic (Figure $4 \mathrm{~b}$ ) than those from the ESE direction through the shallower ocean (see Figure 1). These waves, either from SSE or ESE, are particularly strong in winter (see Figure 6).

An example of the typical pattern in spring (and summer) is shown in Figure $4 \mathrm{c}$, where the waves from the SE reduce their intensity so that wave signals from the other directions, particularly from the southwest (SW) and from the northeast (NE) to east-northeast (ENE), become more visible. These waves may be interpreted as edge waves trapped by reflections from the coast and refractions backward from the Nankai Trough to propagate through the corridor in between. Figure $4 \mathrm{~d}$ shows the impact of Typhoon Man-yi on 14 September, 2013, where it was located on the Philippine Sea far to the south of the network as sketched in the inset of Figure 1 (Japan Meteorological Agency (JMA); www.jma.go.jp/ jma/jma-eng/jma-center/rsmc-hp-pub-eg/trackarchives. html). This typhoon moved from a back azimuth of $175^{\circ}$ to $193^{\circ}$ during the day and amplified the IG waves incoming from the SSE direction, and even more greatly from the NE to ENE direction, whereas those incoming from the ESE remained weak. Strengthening of IG waves from the NE to ENE direction is commonly observed when a typhoon is reported to be on the Philippine Sea, regardless of the exact incoming direction of IG waves originated by the typhoon, which varies widely in a range between the SSE and SW. These observations suggest that the amplified IG waves from the NE to ENE direction were generated secondarily at far distances from the primary (typhoon) source.

We measured the incoming direction of the most energetic IG waves during the 3-year period. In the subsequent discussion, we show only the results from the pressure records, which are in agreement with those from the displacement records within an error of $5^{\circ}$. Figure 5 shows a histogram of the measured incoming direction. The SE direction dominates, although the detail is composed of two closely adjacent directions with a clear gap in between: one is SSE in a range of $140^{\circ}$ to $160^{\circ}$ (measured clockwise from the north) and the other is ESE in a range of $110^{\circ}$ to $130^{\circ}$, which account for $40 \%$ and $32 \%$ of the total measurements, respectively. Together, these two 


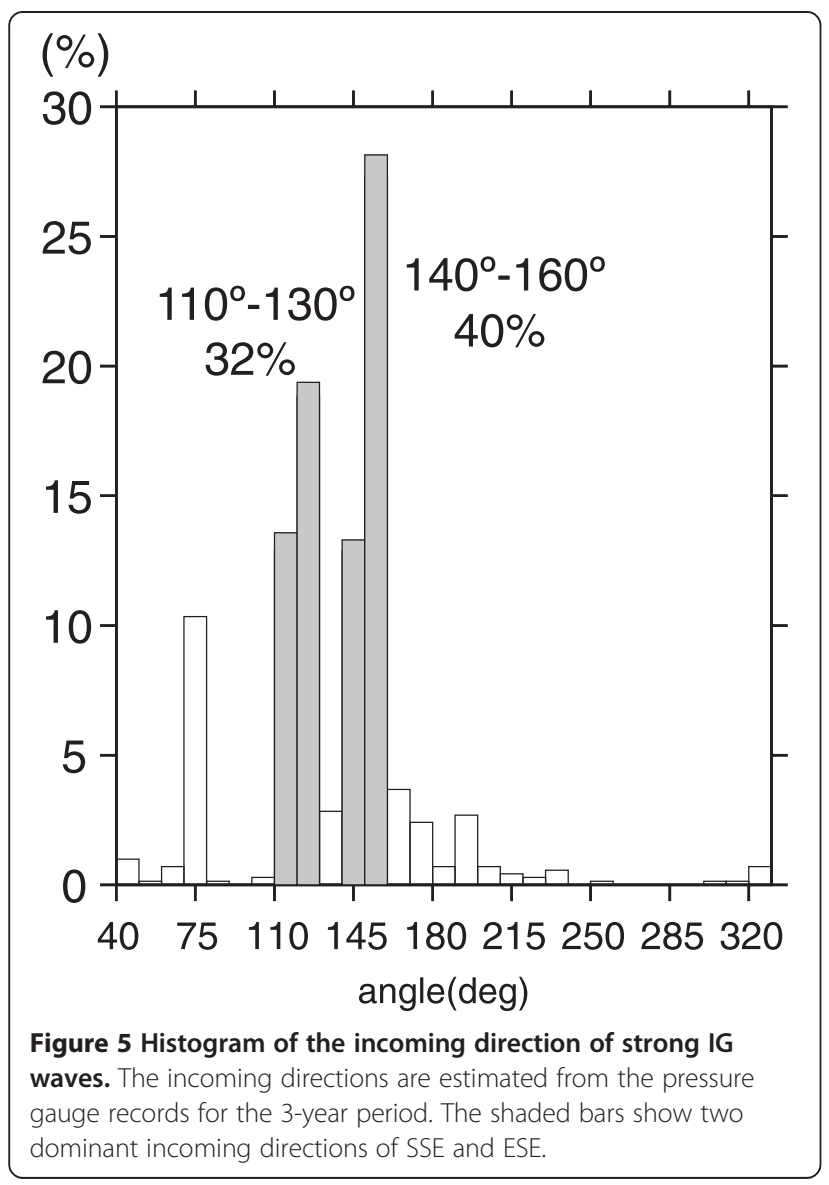

directions account for $72 \%$ of the measurements. Figure $6 a$ shows the daily variations of the incoming direction of the most energetic IG waves throughout the 3 years, where the color indicates the PSD value. The seasonal variations of the incoming directions are clarified by Figure $6 \mathrm{~b}$, in which the results for each of 3 years are superimposed. Several features can be observed from this figure: (1) The SSE and ESE persist as the dominant incident directions; (2) the energy of the IG wave incoming from these two directions shows the same seasonal variations of strong in winter and weak in summer; and (3) in summer, strong waves occasionally are incoming from the other directions. To explore observation (3) in detail, we divided the plots in Figure $6 \mathrm{~b}$ into two as Figure $6 \mathrm{c}, \mathrm{d}$. The plots in Figure $6 \mathrm{~d}$ are limited to the days on which the JMA reported a typhoon or typhoons on the Philippine Sea, whereas the plots in Figure $6 c$ exclude such days. Figure $6 c$ reinforces observations (1) and (2), which imply two distinct excitation sources of IG waves which are spatially stable and seasonally varying synchronously. Figure $6 \mathrm{~d}$ indicates that the typhoon-associated IG waves are incoming from separate directions, one more or less directly from the typhoon in the SSE (as shown in Figure $4 \mathrm{~d}$ ) to SW and the other apparently from the submarine topographic high in the NE to ENE. IG waves incoming from this direction are often more energetic than those directly from the source on the typhoon's track. It is noted that the wave amplitudes from the two stationary sources in the SSE and ESE directions remained largely unchanged, even in the days where a typhoon was reported to be on the Philippine Sea.

\section{Discussion}

We have identified two distinct excitation sources of IG waves in the SSE and ESE directions away from the network. Figure 7 shows that the IG waves from these two sources have different spectral characteristics. If we search for the source using the lower-frequency components $(0.005$ to $0.01 \mathrm{~Hz})$, it is dominantly located in the SSE window $\left(140^{\circ}\right.$ to $\left.160^{\circ}\right)$ as shown in Figure $7 \mathrm{a}$, which accounts for $60 \%$ of the total measurements. If, on the other hand, search is made for the source using the higher-frequency components $(0.01$ to $0.025 \mathrm{~Hz})$, it is dominantly located in the ESE window $\left(110^{\circ}\right.$ to $\left.130^{\circ}\right)$ as shown in Figure $7 \mathrm{~b}$, which accounts for $52 \%$ of the total measurements. Clearly, lower-frequency IG waves are incoming more dominantly from the SSE than from the ESE. Higher-frequency IG waves are incoming more dominantly from the ESE than SSE but also include other incoming directions of $40^{\circ}$ to $80^{\circ}(16 \%), 190^{\circ}$ to $230^{\circ}(13 \%)$, and $300^{\circ}$ to $330^{\circ}(2 \%)$. The signal intensities in the higher frequency range are in general weaker than those in the lower frequency range as shown by the difference of detected IG wave PSD amplitude. This is in part because the higher-frequency IG wave decreases its amplitude more rapidly with depth than the lowerfrequency IG wave. Although Figure 4c,d shows relatively large power in the NW direction $\left(300^{\circ}\right.$ to $\left.330^{\circ}\right)$, the waves from this direction are usually very weak as compared to those from the SE direction (Figure 4a,b). The most energetic waves incoming from the SE direction are poorly accompanied by reflections from the nearest coast, where wave scattering, wave-wave conversion, and dissipation may be significant. As illustrated in Figure 1, the ocean in the ESE window is shallower with larger and more densely populated islands, whereas the ocean in the SSE window is deeper with smaller and more sparsely populated islands. We suggest that the spectral difference between the two azimuthal windows (Figure 7) reflects these differences in seafloor topography, which should affect the processes of generation and propagation of IG waves. In Figure 1, we added the inverse refraction diagram for a very long IG wave incoming to the array, which was obtained by combining the Tsunami Travel Times (TTT) software (Wessel 2009) with the bathymetry data of ETOPO1 (www.ngdc. noaa.gov/mgg/global/global.html). This diagram demonstrates that the wave front of the long IG wave in the 


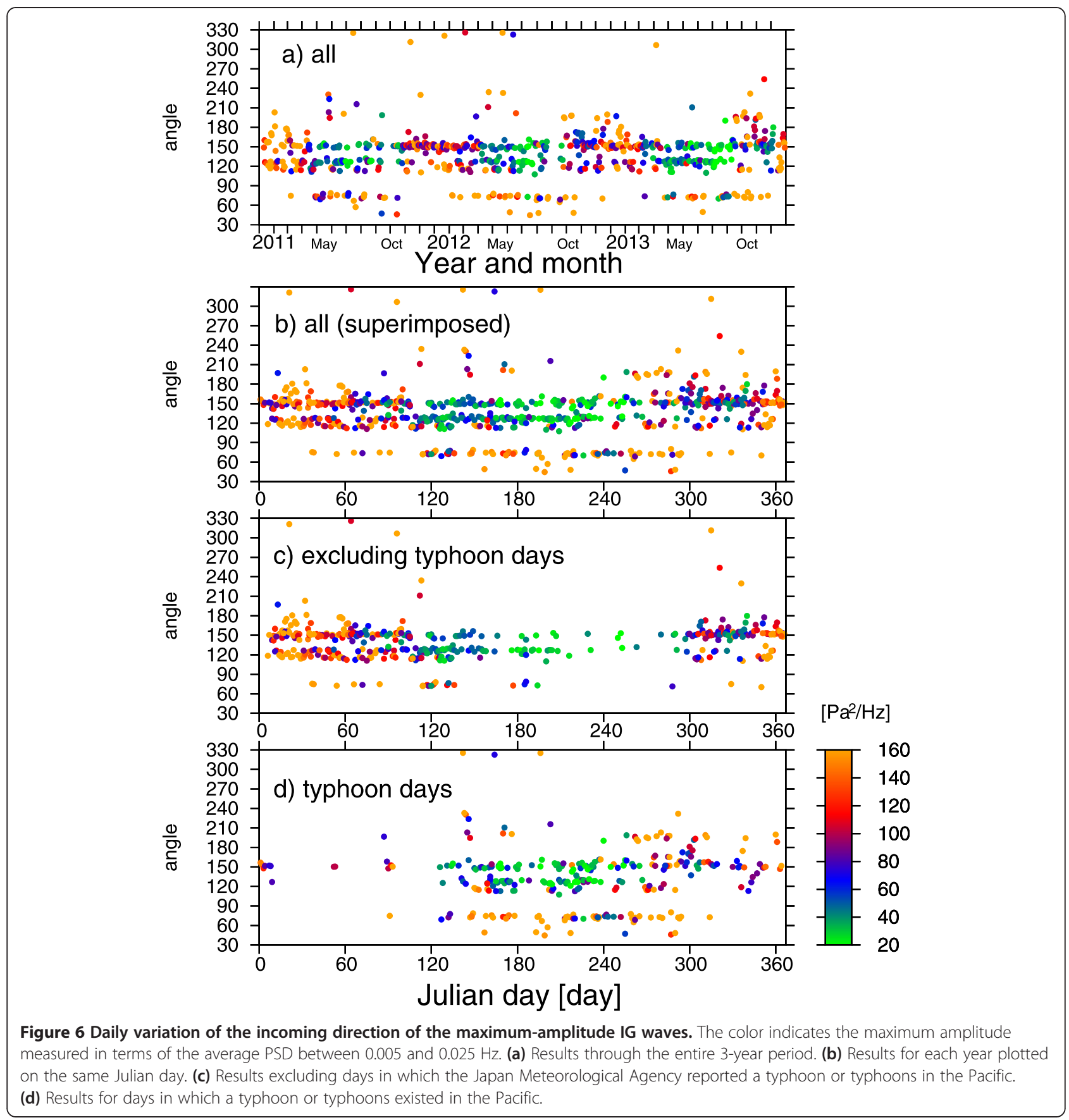

ESE widow is more strongly distorted by the seafloor complexity than that in the SSE window. Although the DONET alone cannot locate the sources in the ESE and SSE windows, installation of a temporal seafloor array in the southeast window, e.g., near the Torishima Island (Figure 1), may suffice to determine these two source locations simultaneously.

Besides the stationary sources discussed above, IG waves can be generated sporadically by extreme weather, typically by typhoons. The incoming direction of the typhoon-originated IG waves depends in a seemingly complex way on the past track of the moving typhoon, as shown in the inset of Figure 1. Most unexpectedly, a typhoon to the south far from the network always enhances IG waves incoming from the NE to ENE direction (Figure 6d). The enhanced IG waves are often more energetic than those directly from the source region (Figure 4d), suggesting some amplification mechanism at the secondary source at distances far away from the primary source. 


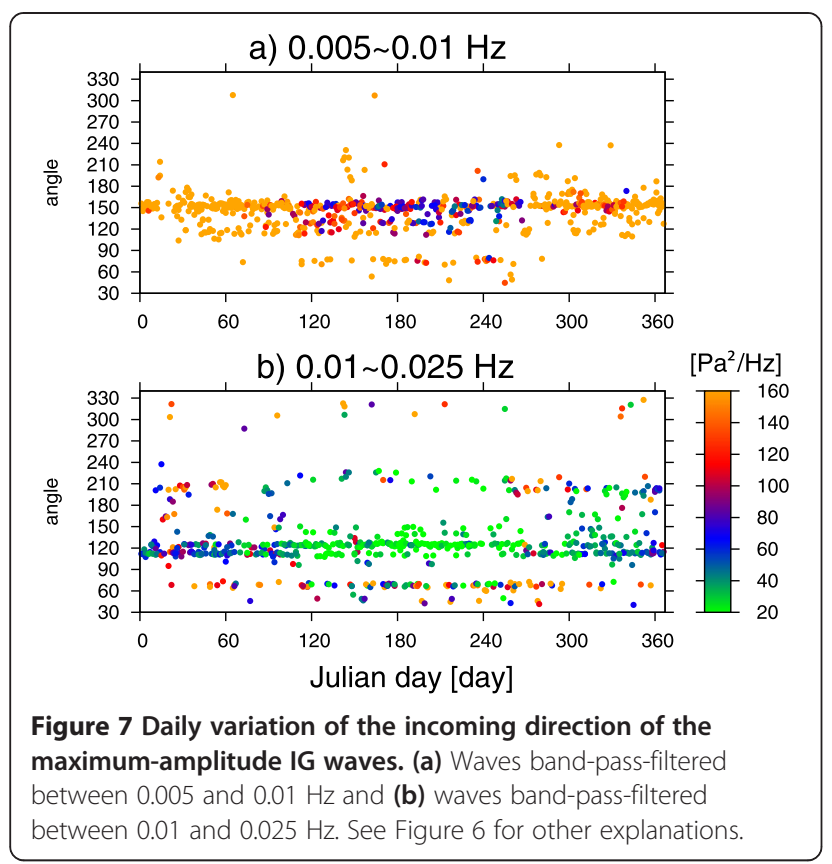

\section{Conclusion}

Although IG waves are known to be a ubiquitously observable phenomenon (Webb et al. 1991), this does not necessarily mean that IG waves are generated everywhere in the ocean. We have identified persistent, energetic IG sources in two azimuthal windows SSE and ESE of the network. The identified sources are rather localized and remain geographically stationary but show seasonally varying intensities of strong in winter and weak in summer. Higher-frequency waves are more dominantly incoming from the shallower ocean with more complex seafloor topography in the ESE direction. Lower-frequency waves are more dominantly incoming from the deeper ocean with less complex seafloor topography in the SSE direction. As shown in Figures $4 \mathrm{c}$ and $7 \mathrm{~b}$, an additional remarkable observation was the persistence of feeble IG waves incoming from the SW direction and from the NE-ENE directions, which may be interpreted as edge waves generated by reflections from the coast and refractions backward from the Nankai Trough to propagate as trapped waves in between. In particular, IG waves incoming from the NEENE directions are greatly amplified when IG waves originated by a typhoon on the Philippine Sea are incident. The amplified amplitudes often well exceed the amplitudes of incident waves from the primary origin. A seafloor network equipped with broadband oceanbottom seismometers and pressure gauges, such as the DONET, is highly useful for detecting IG waves and observing the related phenomena.

\section{Competing interests}

The authors declare that they have no competing interests.

\section{Authors' contributions}

YT, KN, and YF conceived and designed the study; AT and NT acquired the data; $Y T, K N$, and $Y F$ performed the analysis and interpretation of data; YT drafted the manuscript; and YF made a critical revision of the manuscript. All authors read and approved the final manuscript.

\section{Acknowledgements}

The Generic Mapping Tools (Wessel and Smith 1991) and Seismic Analysis Code (Goldstein et al. 1998) were used in this study. A part of the DONET data is available from http://www.jamstec.go.jp/donetevent/NINJA/top.do. We thank Dai Suetsugu for all his help. We also thank two anonymous reviewers and the associate editor (Azusa Nishizawa) for many constructive comments.

\section{Author details}

${ }^{1}$ Department of Deep Earth Structure and Dynamics Research, Japan Agency for Marine-Earth Science and Technology, 3173-25, Showa-machi, Kanazawa-ku, Yokohama, Kanagawa 236-0001, Japan. Earthquake Research Institute, University of Tokyo, 1-1-1, Yayoi, Bunkyo-ku, Tokyo 113-0032, Japan. ${ }^{3}$ Research and Development Center for Earthquake and Tsunami, Japan Agency for Marine-Earth Science and Technology, 3173-25, Showa-machi, Kanazawa-ku, Yokohama, Kanagawa 236-0001, Japan.

Received: 6 June 2014 Accepted: 16 August 2014

Published: 26 August 2014

\section{References}

Crawford WC, Webb SC, Hildebrand JA (1991) Seafloor compliance observed by long-period pressure and displacement measurements. J Geophys Res 96:16,151-16,160, doi:10.1029/91JB01577

Dolenc D, Romanowicz B, Stakes D, McGill P, Neuhauser D (2005) Observations of infragravity waves at the Monterey ocean bottom broadband station (MOBB). Geochem Geophys Geosyst 6, Q09002, doi:10.1029/2005GC000988

Fukao Y, Nishida K, Kobayashi N (2010) Seafloor topography, ocean infragravity waves, and background Love and Rayleigh waves. J Geophys Res 115, B04302, doi:10.1029/2009JB006678

Godin OA, Zabotin NA, Sheehan AF, Yang Z, Collins JA (2013) Power spectra of infragravity waves in a deep ocean. Geophys Res Lett 40:2159-2165, doi:10.1002/grl.50418

Goldstein P, Dodge D, Firpo M, Ruppert S (1998) What's new in SAC2000? Enhanced processing and database access. Seismological Research Lett 69:202-205

Guza RT, Thornton EB (1982) Swash oscillations on a natural beach. J Geophys Res 87:483-491, doi:10.1029/JC087iC01p00483

Harmon N, Henstock T, Srokosz M, Tilmann F, Rietbrock A, Barton P (2012) Infragravity wave source regions determined from ambient noise correlation. Geophys Res Lett 39, L04604, doi:10.1029/2011GL050414

Herbers THC, Elager S, Guza RT (1995) Generation and propagation of infragravity waves. J Geophys Res 100:24,863-24,872, doi:10.1029/95JC02680

Kaneda Y (2010) The advanced ocean floor real time monitoring system for mega thrust earthquakes and tsunamis. In: Application of DONET and DONET2 data to seismological research and disaster mitigation., MTS/IEEE OCEANS 2010

Kawaguchi K, Araki E, Kaneko S, Nishida T, Komine T (2010) Subsea engineering ROV and seafloor observatory construction. In: Proceedings of international symposium on underwater technology 2010/international workshop on scientific use of submarine cables and related technologies 2010, SSC111019, CD-ROM

Longuet-Higgins MS, Stewart RW (1962) Radiation stress and mass transport in gravity waves, with application to 'surf beat'. J Fluid Mech 13:481-504

Nakano M, Nakamura T, Kamiya S, Ohori M, Kaneda Y (2013) Intensive seismic activity around the Nankai trough revealed by DONET ocean-floor seismic observations. Earth Planets Space 65:5-15, doi:10.5047/eps.2012.05.013

Nishida K (2013) Earth's background free oscillations. Annu Rev Earth Planet Sci 41:719-740, doi:10.1146/annurev-earth-050212-124020

Nishida K, Kawakatsu H, Fukao Y, Obara K (2008) Background Love and Rayleigh waves simultaneously generated at the Pacific Ocean floors. Source distribution of Earth's background oscillations. Geophys Res Lett 35:L16307

Nishida K, Fukao Y, Watada S, Kobayashi N, Tahira M, Suda N, Nawa K, Oi T, Kitajima T (2005) Array observation of background atmospheric waves in the 
seismic band from $1 \mathrm{mHz}$ to $0.5 \mathrm{~Hz}$. Geophys J Int 162:824-840, doi:10.1111/ j.1365-246X.2005.02677.x

Okihiro M, Guza RT (1995) Infragravity energy modulation by tides. J Geophys Res 100:16,143-16,148, doi:10.1029/95JC01545

Rhie J, Romanowicz B (2006) A study of the relation between ocean storms and the Earth's hum. Geochem Geophys Geosyst 7, Q10004, doi:10.1029/ 2006GC001274

Rhie J, Romanowicz B (2004) Excitation of Earth's continuous oscillations by atmosphere-ocean-seafloor coupling. Nature 431:552-556, doi:10.1038/ nature02942

Rost S, Thomas C (2002) Array seismology: methods and applications. Rev Geophys 40(3):1008, doi:10.1029/2000RG000100

Sugioka H, Fukao Y, Kanazawa T (2010) Evidence for infragravity wave-tide resonance in deep oceans. Nat Commun 1:84, doi:10.1038/ncomms1083

Tanimoto T (2005) The oceanic excitation hypothesis for continuous oscillations of the Earth. Geophys J Int 160:276-288, doi:10.1111/j.1365-246X.2004.02484.x

Tomson J, Elgar S, Raubenheimer B, Herber THC, Guza RT (2006) Tidal modulation of infragravity waves via nonlinear energy losses in the surfzone. Geophys Res Lett 33, L05601, doi:10.1029/2005GL025514

Webb SC, Zhang X, Crawford W (1991) Infragravity wave in the deep ocean. J Geophys Res 96:16,151-16,160, doi:10.1029/90JC02212

Wessel P (2009) Analysis of observed and predicted tsunami travel times for the Pacific and Indian oceans. Pure Appl Geophys 166(1-2):301-324

Wessel P, Smith WHF (1991) Free software helps map and display data. Eos Trans AGU 72:441

doi:10.1186/1880-5981-66-99

Cite this article as: Tono et al:: Source characteristics of ocean

infragravity waves in the Philippine Sea: analysis of 3-year continuous

network records of seafloor motion and pressure. Earth, Planets and

Space 2014 66:99.

\section{Submit your manuscript to a SpringerOpen ${ }^{\circ}$ journal and benefit from:}

- Convenient online submission

- Rigorous peer review

- Immediate publication on acceptance

- Open access: articles freely available online

- High visibility within the field

- Retaining the copyright to your article

Submit your next manuscript at $\gg$ springeropen.com 